30 ANOS DO MCTI

\section{Estabilidade e responsabilidade na política de inovação são principais marcas}

Nas eleições para governador do Maranhão, em 1965, o candidato Renato Archer, do PTB, partido próximo dos movimentos trabalhistas, foi derrotado pelo candidato José Sarney, da UDN. Um mês depois, o governo militar, descontente com os resultados eleitorais, extinguiu os dois partidos. Sarney foi para a Arena, mais próximo do governo; Archer, para o MDB, da oposição possível naquele momento. Vinte anos mais tarde, Tancredo Neves foi eleito, de modo indireto, para presidir o Brasil. Seu vice era José Sarney. Tancredo prometera, durante a campanha, fortalecer a ciência no Brasil. Não havia melhor nome para o Ministério de Ciência e Tecnologia (MCT) que ele pretendia criar do que Renato Archer. Tancredo morreu pouco depois das eleiçôes, Sarney tornou-se presidente, e, com o ministério criado, Archer foi escolhido para ser o ministro de Ciência e Tecnologia. Assim, a Nova República acabou colocando Sarney e Archer do mesmo lado. A convivência dos antigos adversários políticos, no entanto, foi um desafio menor do que consolidar o ministé- rio recém-criado em um cenário de grandes dificuldades na economia. Para o governo democrático que assumia, havia a imensa tarefa de acertar as contas deixadas pelos militares. Logo nos primeiros meses após tomar posse como presidente, Sarney lançou o Plano Cruzado, que resultou no controle temporário da inflação e aumentou o salário real. Houve certa euforia popular, que não durou muito. Na sequência, uma combinação de más políticas com planos econômicos mal sucedidos gerou um cenário devastador, com hiperinflação, Estado fortemente endividado e contas externas insustentáveis.

Nesse cenário, o MCT não era prioridade da distribuição orçamentária do governo. Nem uma sala própria para o ministro havia. O MCT passou um tempo em um espaço improvisado. A falta de verbas para a ciência no Brasil não era, contudo, grande novidade. Entre $1871 \mathrm{e}$ 1882, por exemplo, o astrônomo francês Emmanuel Liais, que dirigiu o Imperial Observatório do Rio de Janeiro, queixou-se seguidas vezes aos ministros do Império sobre os limitados recursos financeiros para comandar a instituição e da falta de mecanismos para divulgar os resultados ali obtidos. Quase um século depois, a situação não melhorara muito. Ao ser criado, o orçamento do MCT era de pouco mais de 2 trilhões e meio de cruzados, um dos menores orçamentos ministeriais.
Além disso, 36\% desse montante já estava comprometido com pagamento de pessoal.

CREDIBILIDADE A despeito da falta de dinheiro, uma mudança importante aconteceu com a vinculação ao novo ministério da Financiadora de Estudos e Projetos (Finep) e do Conselho Nacional de Desenvolvimento Científico e Tecnológico (CNPq), dando início, assim, a uma política nacional mais efetiva de ciência e tecnologia. Durante o período agudo de repressão e censura do governo militar, não havia um órgão centralizador da política de C\&T. Boa parte das diretrizes vinha da Sociedade Brasileira para o Progresso da Ciência (SBPC) que não tinha livre trânsito no governo ditatorial. A criação do MCT, tendo Renato Archer como ministro, homem que gozava de credibilidade junto à comunidade científica, resultou em uma aproximação dessa comunidade do centro decisório da política federal de C\&T.

Essa política, porém, não deslanchou de imediato. Archer perdeu batalhas importantes pela melhora da condução das diretrizes para $\mathrm{C} \& \mathrm{~T}$. Por exemplo, apesar de acreditar que a Secretaria de Tecnologia Industrial (STI) deveria estar subordinada ao MCT, e que sem o órgão não seria possível fazer uma adequada política tecnológica nacional, a STI permaneceu subordinada ao Ministério da Indústria e Comércio. 


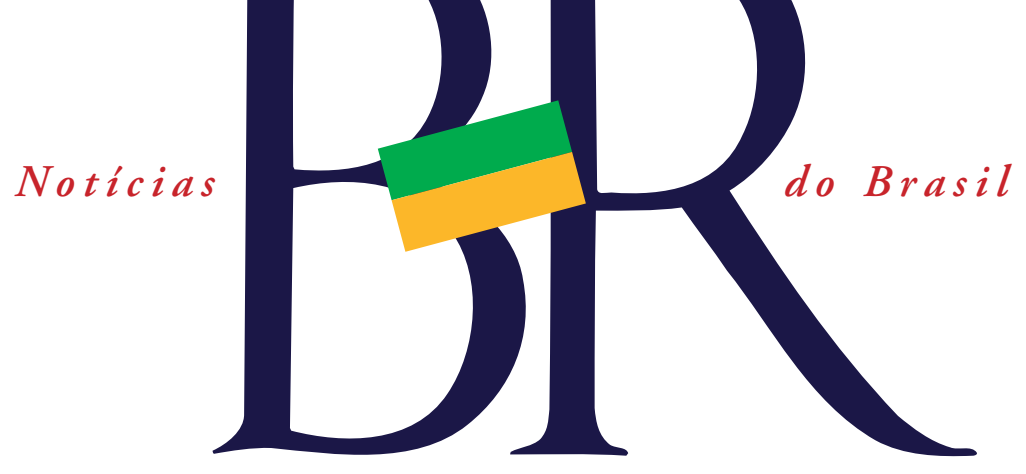

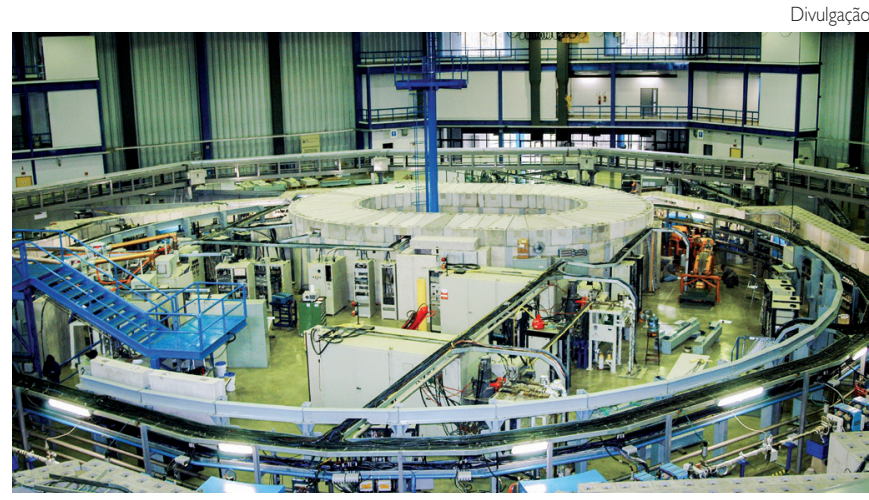

Laboratório Nacional de Luz Síncrotron é um dos maiores projetos do MCTI à implementação do projeto e onze anos mais tarde, em 1997, em Campinas (SP), o LNLS foi inaugurado e continua sendo, até hoje, o único laboratório desse tipo em toda a América Latina, recebendo anualmente diver-

Em um percurso de idas e vindas e sempre com orçamento apertado, o MCT definiu os primeiros contornos para uma política de ciência e tecnologia, priorizando áreas como biotecnologia e química fina, além de aumentar o número de bolsas concedidas a pesquisadores. Outro importante avanço foi obtido na cooperação internacional com países do Sul. Foi graças ao MCT e a Archer que o Brasil firmou um acordo com a China para o programa CBERS (China-Brazil Earth Satellite Resources), marco fundamental para as relaçóes Sul-Sul da política externa nacional e que ainda hoje colhe resultados.

Conquista igualmente importante foi obtida em 1985, após uma missão de cientistas brasileiros fazer estágio de 3 meses no Stanford Linear Accelerator Center (SLAC), nos Estados Unidos. A partir dessa missão começou a ser idealizado o Laboratório Nacional de Luz Síncroton (LNLS). Alguns meses mais tarde, em janeiro de 1986, o governo federal deu parecer favorável sos pesquisadores de múltiplas áreas. Hoje o LNLS integra o Centro Nacional de Pesquisa em Energia e Materiais (CNPEM), responsável pela gestão de outros três laboratórios de referência nas áreas de biociências, bioetanol e nanotecnologia.

INSTABILIDADE Ainda assim, o MCT continuou desvalorizado pelo governo. Seja pela crise econômica que se alastrava ou por pressões políticas internas, não havia suficiente apoio para a pasta, que vivia entre a precariedade e a instabilidade institucional. Entre 1985, ano de sua criação, e 1992, período que compreende os governos de Sarney e de seu sucessor Fernando Collor de Mello, o ministério teve nove titulares. Já entre 1992 e 2015, após o início do governo de Itamar Franco e até o presente momento, 10 ministros assumiram a pasta.

Mais grave do que a rotatividade de ministros, contudo, foi a mudança de situação do próprio ministério. Após ter sido fundido ao Ministé- rio do Desenvolvimento, Indústria e Comércio, em 1989, durante uma reforma ministerial desastrosa conduzida pelo governo Sarney, e depois ser transformado em uma secretaria, o MCT voltou a existir no mesmo ano. Um ano depois, já no governo Collor, devido a uma política drástica de corte de gastos governamentais, foi novamente extinto. Ressurgiu apenas 1992, no governo Itamar Franco, por meio de uma medida provisória.

Assim, somente a partir da década de 1990, nos governos de Fernando Henrique Cardoso e Luiz Inácio Lula da Silva, o MCT passa a contar com maior apoio do governo. No segundo mandato de FHC, por meio de ampla mudança regulatória e, sobretudo, do mecanismo de financiamento de fundos setoriais, a inovação passou a ser de responsabilidade do ministério. Isso ocorreu em sintonia com o que se passava em outros países do mundo, que davam maior importância à atividade inovativa.

Os fundos setoriais representaram uma mudança importante ao direcionar investimentos em CT\&I a setores considerados estratégicos, como por exemplo, o de petróleo, agronegócio, biotecnologia e transporte. Administrados pela Finep, eles utilizam recursos oriundos de receitas vinculadas por leis específicas, favorecendo um tipo de apoio de longo prazo, voltado para o setor produtivo e para o desenvolvimento econômico. 


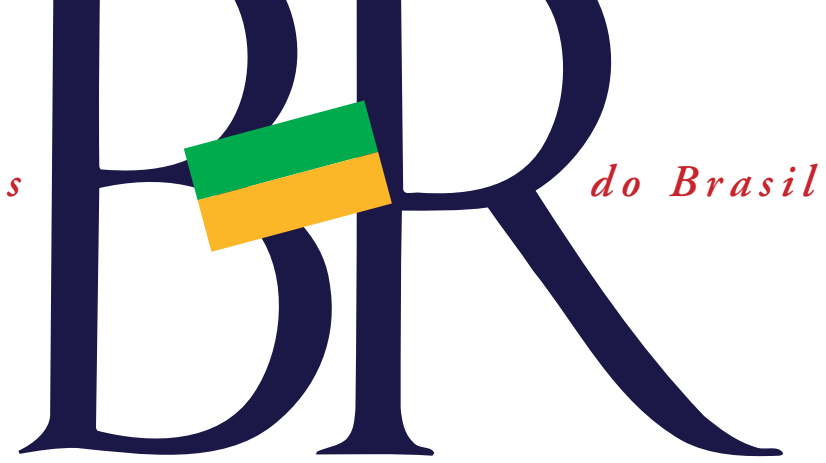

POLÍTICA PARA INOVAÇÃo No governo Lula, a diretriz fortemente voltada para a inovação não foi alterada e leis importantes para a inovação foram criadas. Entre elas, a Lei da Inovação (2005) e a Lei do Bem (2006), que, se não lograram alterar profundamente números relativos à atividade inovativa no Brasil, no mínimo deram consistência jurídica e trouxeram avanços na área. Os avanços relativos à inovação continuaram no primeiro mandato do governo atual. O MCT teve até mesmo seu nome mudado para Ministério da Ciência, Tecnologia e Inovação (MCTI).

No presente momento, o país passa, contudo, por outro período de turbulência econômica. A situação, porém, é bastante distinta daquela dos governos Sarney e Collor. Fortalecido desde o governo Itamar Franco, o MCTI já tem autonomia suficiente, legal e de fato, para sustentar a política de ciência, tecnologia e inovação nacional. A despeito dos contingenciamentos orçamentários aos quais o ministério possa ser submetido, a importância dessa pasta na condução de uma política para ciência e tecnologia parece estar consolidada, afastando, assim, todos os riscos de sua extinção. No marco de seus 30 anos, a principal discussão é como ampliar suas ações em um momento de orçamento restrito.

Ricardo Manini
SAÚDE PÚBLICA

70 anos de fluoretação da água de abastecimento público requer debate

Em 1945, Grand Rapids, no estado do Michigan, nos Estados Unidos, tornou-se a primeira cidade no mundo a receber água fluoretada artificialmente. A medida reduziu em $50 \%$ a incidência de cáries.

Setenta anos depois, o programa de fluoretação encontra resistência, sobretudo em relação às quantidades adequadas que devem ser adicionadas e controladas para produzir os efeitos desejados. No Brasil, a Pesquisa Nacional de Saneamento Básico de 2008, apontou que $60,6 \%$ dos municípios agregam flúor "em concentração adequada, à água destinada ao abastecimento público, com o objetivo de prevenir a cárie dental". Não existe, no entanto, um sistema de consulta público da concentração de flúor na água de abastecimento. Segundo dados da Sociedade Britânica de Fluoretação - Brasil é a segunda nação com maior cobertura de flúor na água, depois dos Estados Unidos.

PROGRAMA DE FLUORETAÇÃO No Brasil, a cidade de Baixo Gandu (ES)foi a primeira a fluoretar a água em 1953, mas apenas em

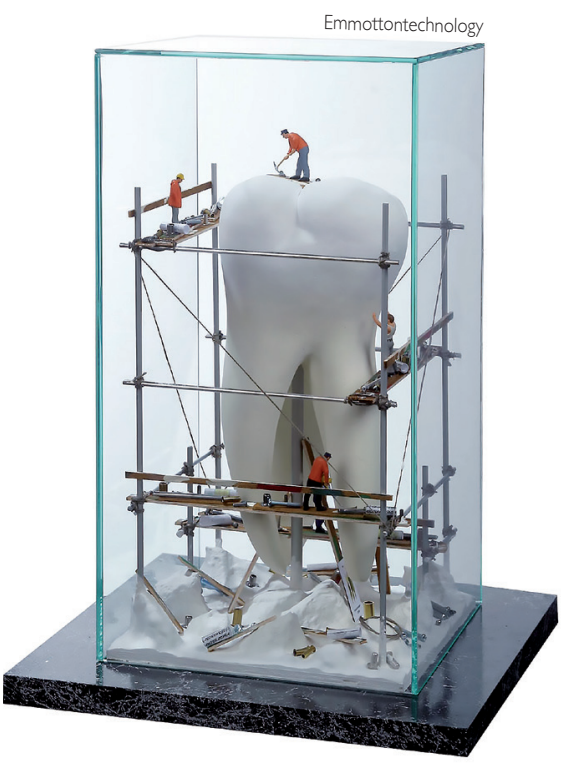

Under construction é obra da Art 4 your practice

1974 a fluoretação se tornaria obrigatória, através da Lei Federal n6050, regulamentada por decreto um ano depois. A Portaria do Ministério da Saúde n 635/BSB (1975) estabelece que, de acordo com as médias das temperaturas máximas diárias de cada localidade, variando entre $10^{\circ} \mathrm{C}$ e $32,5^{\circ} \mathrm{C}$, a concentração de flúor deve variar entre 0,6 e 1,7 partes por milhão (ppm). Em 2011, a concentração máxima de flúor foi alterada para 1,5ppm, equivalente a 1,5 miligramas de flúor por litro de água, através da Portaria n 2.914 do Ministério da Saúde. Na América do Sul e na Europa, a maioria dos países que possui fluoretação da água, permite no máximo 1,5ppm 